The International Journal of Digital Accounting Research

Vol. 8, N. 14, 2008, pp. 97-135

ISSN: $1577-8517$

\title{
Reengineering Business Reporting Creating a Test Bed for Technology Driven Reporting
}

\author{
Miklos A. Vasarhelyi. Rutgers Business School, Newark, NJ. USA. \\ miklosv@andromeda.rutgers.edu.
}

Michael G. Alles. Rutgers Business School, Newark, NJ. USA.

alles@ rbsmail.rutgers.edu

\begin{abstract}
Building on the work originally done for the Enhanced Business Reporting consortium of the AICPA, this paper develops a test bed for innovation in business reporting. As with flying test beds in aviation, the object is to explore the impact of new technologies and techniques rather than to create a product intended for immediate implementation. The starting point of our analysis is that if the financial reporting system was being built from scratch today, it would look very different, taking into account fundamental changes in the two drivers of financial reporting: First, the dominance of market making by professional investors, which includes such intermediaries as pension and mutual funds, which is how most ordinary individuals interact with the market; Second, the reduction in the variable costs of disclosures to technology-enabled firms, while time taking a broader view of the cost of reporting to include the opportunity cost to the firm from faulty disclosures and the cost to professional investors of having to extract the data they need from statements that were not designed for their needs. Taken together, the consequence of these two changes is that a system being designed today has to rethink the entire process by which financial data held by the firm is translated into decision relevant information by users. This process takes place both within the firm and outside of it, with a handover of financial statements taking place at the boundary between the firm and its users. Given these changes it is time to ask whether the location of that handover boundary point is still appropriate: whether the firm should continue to aggregate and condense information extensively before releasing it, or whether sophisticated users would prefer to have access to more information in closer to its raw format so that they can manipulate and aggregate it as they
\end{abstract}

Submitted October 2006

DOI: 10.4192/1577-8517-v8_5

Accepted March 2008 
see fit. Based on this conceptual model we discuss the building blocks of a 21 st century reporting system and the technical architecture needed to implement it. It is our hope that this paper will help create an open source test bed that will develop new ways to measure, manage and communicate firm performance in the 21 st century.

Key words: Financial reporting, GAAP, AIS, business measurement.

\section{INTRODUCTION}

\section{Creating a Test Bed for Innovation}

There is a long history in aviation of creating flying test beds: aircraft that provides the means to test new and emerging technologies, but which are not intended to go into mass production. For example, NASA's X-29 plane explored the use of advanced composites in aircraft construction, a unique forward-swept wing and a computerized fly-by-wire flight control system, amongst other innovations. The forward swept wing was the aircraft's most noticeable feature, with the odd shape promising unprecedented maneuverability and high speed. The problem with this design, however, is that it makes the aircraft exceptionally prone to instability in flight and it only avoids crashing because much of the flying is done by a computer which makes necessary continuous adjustments of the plane's controls to keep it stable - a process that no human pilot could accomplish in time.

The concept of a test bed for emerging technologies is exactly what we are attempting to do with this project to reengineer financial reporting. And as with any test bed, the aim of this project is not the creation of a system of financial reporting that can or should be implemented in practice as is, but rather, to explore the role that the information technology can play in shaping the nature and characteristics of financial reporting. The analogy to the X-29 also arises from the fact that the kind of reporting system we envisage cannot exist without that technology, both because it is the means by which firms in the digital economy create value and because it provides the capability for measuring and communicating that value. 


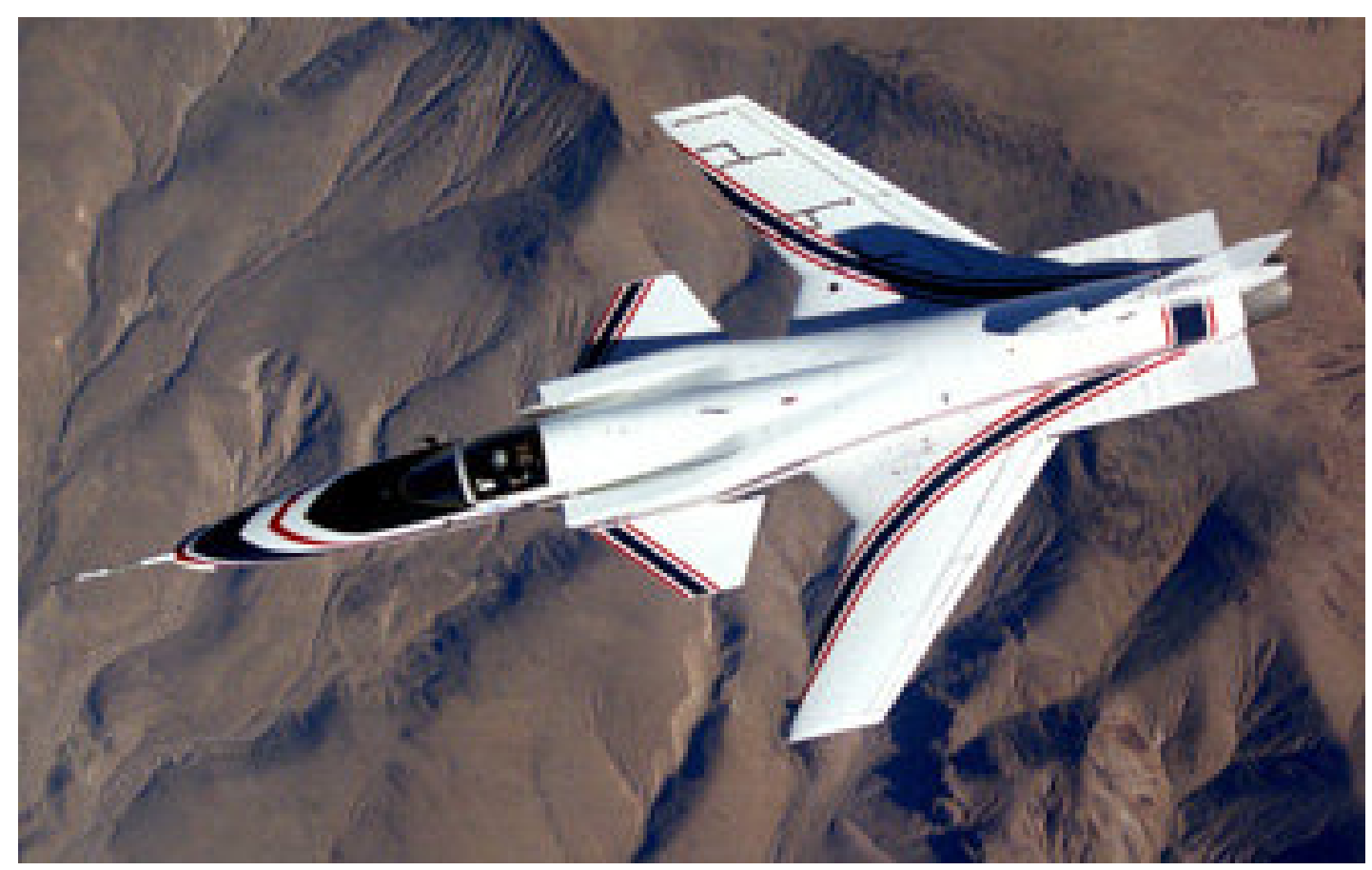

Figure 1. X-29 Test Bed

\section{Improving Financial Reporting}

Throughout the history of accounting there have been initiatives to update or change the basis of financial accounting, no more so than in the last few years, after scandals such as those at Enron and WorldCom shook public confidence in financial reporting. To pick but a few of the more prominent examples, the CICA undertook its Canadian Performance Reporting Initiative that distinguished measuring and reporting "value creation" from "value realization", the latter, it is argued, being the focus of the current system of accounting. The IASB and the FASB are currently undertaking a major initiative to jointly develop an improved conceptual framework for financial reporting, building on the earlier FASB's Concepts Statements and the IASB's Framework for the Preparation and Presentation of Financial Statements. This process will necessitate re-examining some of the thorniest issues that have faced accountants from the very beginning of the profession, such as the definition and scope of earnings, the basis for the valuation of assets and the impact of uncertainty. Meanwhile the CFA Institute has just released its Comprehensive Business Reporting Model that proposes changes to the accounting system that is specifically aimed at meeting the needs of investors. 
All these projects, and the many others before and ongoing, take as their starting point the perceived inability of the current financial reporting paradigm to adequately measure firm performance and capture firm value, as reflected most notably in the increasing importance of intangible assets and the subsequent rise in the market to book ratio. While these efforts vary in the degree of change they promote and in their underlying reporting models (EVA in the Canadian model, for instance), their differences are really ones of emphasis. Few have suggested wholesale changes to the way in which markets obtain financial information, such as moving away from the current system of quarterly and audited annual financial statements, with the focus more on incremental improvement than a total rethink.

What has been lacking, in particular, is an examination of the role that technology has had on dramatically transforming the 21st century business, especially large Fortune 500 firms-beginning with PC's in the 1980s to Enterprise Resource Planning Systems (ERP) such as SAP in the 1990s and the panoply of digital technologies that make up the networked, real time firm of today's "flat economy". The problems these changes pose for financial reporting are well known, with, for example, SEC Commissioner Cynthia A. Glassman recently stating in a talk on "Complexity in Financial Reporting and Disclosure Regulation" that: "The current questions about the ability of our accounting and reporting framework to communicate meaningful information to investors arise, in part, because the economy continues to evolve at a rapid pace, while reporting standards and mechanisms are in a 'catch-up' mode. Globalization and the emergence of new economies and capital markets have increased dramatically. Advances in technology, including the emergence of the Internet, faster and more ubiquitous communication and other technological developments, have changed the way companies do business, as well as changing the types of financial arrangements and instruments that businesses utilize. As the business world has become more complex, so have financial reports and accounting standards." And yet, as in this speech by Commissioner Glassman, the discussion inevitably returns to familiar problems in financial accounting and after having raised the issue, fails to consider the role of technology not just as a source of problems for financial reporting, but also as a solution.

The project we propose here is to complement these other initiatives on reforming financial reporting by a particular focus on the capabilities of technology 
to transform the reporting process: by creating a test bed which can be used to examine new and different technologies for measuring and communicating firm performance that can subsequently be incorporated into a comprehensive new model of business reporting, along with the best ideas from the various other initiatives that stand the test of time.

\section{The "Galileo" Project}

The most direct predecessor of this project is the Enhanced Business Reporting Consortium (EBRC), which defines itself as a consortium of stakeholders collaborating to improve the quality, integrity, and transparency of information used for decision-making in a cost effective, time efficient manner. The EBRC is the successor to the Special Committee for the Enhanced Business Reporting Model, also called the Starr Committee after its chairman Michael Starr from Grant Thornton, which was created by the AICPA in response to the collapse of Enron and Arthur Andersen in 2000.

That committee re-examined the proposals presented in the early nineties by another special committee, the Jenkins Committee. Despite the fact that its chairman, Ed Jenkins, subsequently headed the FASB, only a very small subset of the Jenkins Committee recommendations were put into practice, one reason being that the late 1990s bull market made its concerns about the adequacy of GAAP seem excessive. What the Starr committee would really have liked to have determined was whether the malfeasance crisis could have been avoided if the improvements to financial accounting and reporting suggested in the Jenkins report had been implemented. But since that question is essentially unanswerable, the lesson the committee took away from the fate of the Jenkins recommendations was that the accounting profession by itself did not have the authority or the ability to create a new reporting model, regardless of how good its proposals were. Given the enormous societal consequences of changing the reporting system, bringing about substantive change requires the cooperation of a much broader set of stakeholders in the financial reporting process, and bringing them on board was the rationale for transforming the EBR committee into the Enhanced Business Reporting Consortium. The enhanced business reporting model consists of five elements that are meant to give rise to a more useful and robust system of financial reporting (Figure 2): 


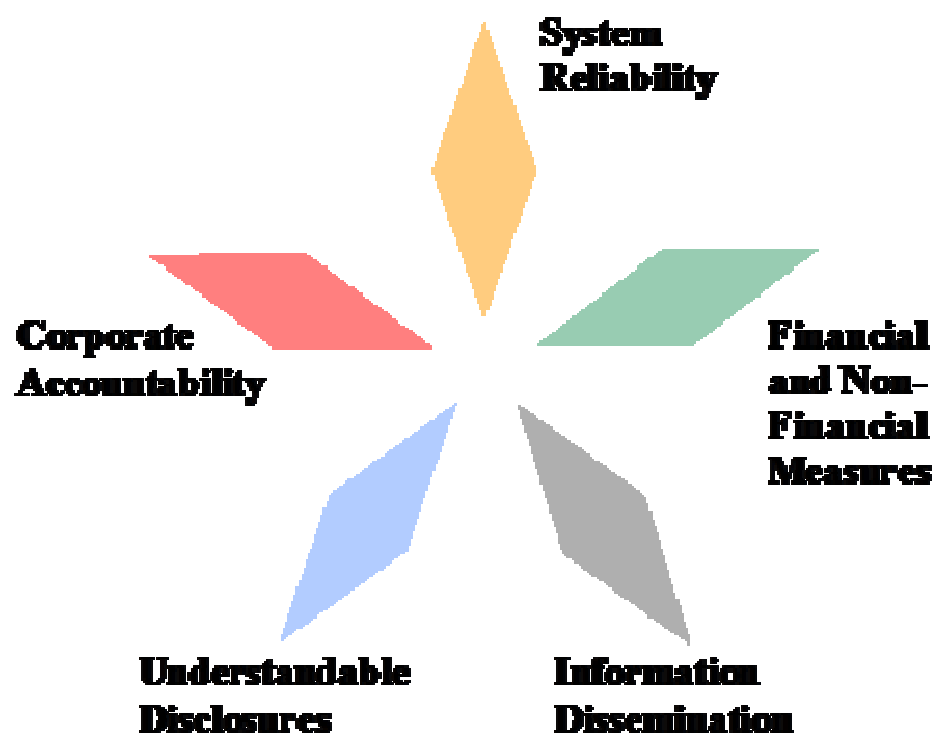

Figure 2: Components of EBRC Model

To help guide the EBRC, the Public Company Taskforce of the Star committee created a set of sample reports that illustrate the kinds of enhanced disclosures that it feels are necessary and useful for complex organizations in today's information economy. By design, most of these sample reports were not especially "radical". The Starr Committee self imposed mandate was developing a structure for voluntary disclosures that "enhanced" the coverage of the statuary annual income statement and balance sheet, as opposed to questioning the underpinnings of those reports themselves, such as the continued relevance of GAAP. As Paul Herring, the chair of the Public Company Task Force wrote during the process that created the sample reports: "Formats that follow outlines that are already in general use in the business information supply chain are likely to gain faster acceptance than those that are new... We will explore potential enhancements to the existing financial reporting format but will not consider wholesale re-structuring of the financial statements." The incremental approach of the EBR process is justified in terms of change management, although as the failure of the Jenkins Committee indicates, caution is by itself no guarantee of acceptance.

The committee did commission one project, known by its internal code name "Galileo", that was by design meant to push the envelope of possible changes to the reporting system. As the EBRC states on its website: "While [the other sample 
reports] present ideas that are potential enhancements to existing reporting, the 'Galileo' sample report presents ideas that are further departures from current practice". The basis of Galileo was the question: What would a reporting system would look like if it was designed from scratch for 21st century firms using 21st century tools for a 21st century audience? It is that emphasis which drives the inevitable focus on technology, because it is technology and all its consequences that define business today.

The other sample reports do not ignore technology, but restrict its use largely for the presentation of reports in a web based rather than paper format. But Galileo went further by not just using it as a medium for communication, but by making the assumption that a new reporting system must logically arise from that IT foundation of the firm and its management.

\section{Towards an Open Source Solution}

The objective of this paper is to help launch an initiative into technology driven business reporting, and to do so in a way that makes use of the characteristics of the information age economy to create an environment for the development of the concept. What we have in mind is the equivalent of the "open source" development model, of which UNIX is the most prominent example, and which stands in contrast to changes in the standard reporting model which have always been led by bodies "authorized" to do so, such as the FASB or the IASB. As EBRC experience demonstrated, such parties are subject to political constraints that constrain the scope of innovation. Of course, the danger is that a radical approach would fail in translating ideas, however innovative, into action. But, again, a more constrained approach has also had little to show for it, and given that one of the characteristics of the 21st century economy is that it is a highly efficient marketplace for ideas, our hope is that the strength of the ideas for business reporting which a new approach might generate will serve as its own endogenous form of change management.

It must be emphasized that this paper does not provide a definitive model of business reporting. Doing so would defeat the purpose of creating an open source community, even if it were possible for one paper to accomplish the creation of a new system of reporting by itself in the first place. Rather, building on the Galileo work originally done for the EBR consortium, this paper puts forward one set of 
ideas and visions with that hope that this will begin a process that will create a shared effort on reengineering business reporting from a technology perspective. Our intention here is to lay out some of the larger forces that will shape any new business reporting model and to describe a general framework to organize the thinking of this nascent movement. What this paper really is intended to do is to invite the participation of all those who feel that we can and must do better in the way in which we measure, manage and communicate firm performance in the $21 \mathrm{st}$ century.

We begin by going over the well known shortcomings of the existing reporting system. Section 3 then discusses the changes in the fundamental drivers of financial reporting and draws out the implications they have on the characteristics of a 21st century reporting system. Section 4 puts forward the building blocks of a test bed that will help develop that system. These building blocks are intended to serve as the foundations upon which a collaborative effort can be initiated to develop the reporting system. Section 5 offers concluding comments.

\section{THE UNDERLYING PROBLEMS OF BUSINESS REPORTING}

The need for drastic change in financial reporting has been recognized by many. When launching the CFA's recommendations for reforming financial reporting to better serve the needs of shareholders, Rebecca T. McEnally, CFA, Ph.D., project director of the Comprehensive Business Reporting Model and director of the Capital Markets Policy Group for the CFA Centre stated: "As businesses develop new products and services, the financial reporting model must keep pace to ensure that financial statements are relevant, clear, accurate, and complete. Investors worldwide are too often in the dark about the true value of companies because accounting practices fail to reflect the economics of today's business operations". Even blunter was Senator Carl Levin, who condemned "the fiction that corporate financial statements had become: companies technically were in compliance with accounting rules, yet their financial statements were hiding huge debts and other liabilities."

There are numerous lists of problems in the current financial reporting system. The measurement and implications on earnings and valuation of intangible assets tops most of those lists, followed by accounting for derivatives and consolidations. The perennial issues of accounting for leases, revenue recognition and non-cash 
compensation remain, while some problems, such as the recognition of uncertainty and the extent to which relevance should trump reliability have dogged accounting since its very inception. Since such issues have been discussed ad nauseum elsewhere, from academic papers to Senate hearings, it would be redundant for us to repeat them here. What is useful, though, is to step back and understand the fundamental basis of financial reporting.

Financial reporting would not be needed if all internal and external stakeholders in the firm shared the same information about how the firm has performed in the past and had similar expectations as to how it will perform in the future. In reality, those within the firm are inevitably in a better position to know its state than those stakeholders outside of it. Moreover, the former are not just informationally advantaged, but as managers they can actually shape the firm's future performance. This is the fundamental informational asymmetry that both motivates and bedevils financial reporting, a reflection of the conflict of interest between shareholders who only care about the financial performance of the firm as reflected in its market price, and managers who can directly benefit from exploiting the firm's assets. Other stakeholders in the company, such as employees, creditors, suppliers, customers, local communities, government agencies and so on have their own points of alignment and conflict with management and look to financial statements to obtain information relevant to their particular decisions.

These informational asymmetry and moral hazard issues add the possibility of deliberately distorted reporting to the already formidable problem of measuring firm performance. Moreover, measuring past firm performance is largely a means towards the end of forecasting future performance, for it is only the future and not the past that affects firm valuation. Clearly managers can affect the degree to which past performance predicts future performance, thus affecting the value of financial reporting.

Adding to these incentive problems are changes in the way in which firms transform capital into returns. Once the main function of the firm was to apply unskilled labor to physical assets, meaning that reporting which concentrated on the disposition of those tangible assets adequately captured firm performance. Indeed, even accuracy in measuring assets could be sacrificed for other goals such as reliability through the doctrine of conservatism without greatly reducing the usefulness of the reports. But firms today create value by the use of such intangible 
assets as knowledge and the skills of its workers with the result that the relationship between its physical assets and its performance is greatly diminished. This creates two problems: a pure measurement issue of how to account for the presence and role of intangibles and an incentive problem in that this weaker relationship opens up a wider scope for managers to manipulate earnings.

An example of these challenges comes from the decision by Cisco Systems, in May 2001, to write-down its inventory by $\$ 2.25$ billion, an amount larger than the inventory value in its books. One explanation is that the write-down related to the value of inventories that could be not sold by its suppliers in the value chain where Cisco had a contractual or moral obligation. In particular, during the e-commerce boom Cisco had offered many of its dot-com customers' vendor financing in exchange for sales contracts, while signing contracts itself with downstream suppliers in anticipation of tight demand. These obligations were not reflected anywhere in the financial statements, thus, in hindsight, clearly overstating the firm's profit potential. Of course, even granting these measurement problems, there was also the suspicion that the sheer magnitude of the write-off resulted from the use of the well known tactic of the "big bath", in which if reporting some bad news is unavoidable, then the best of a bad lot is taken advantage of by writing of all other possible bad news in advance in one shot, thereby creating reserves to boost income in the future.

This example and the difficulty in disentangling its purpose are indicative of the difficulty that users face today with financial reports. This is not an example of fraud, but rather an example of what is arguably a far more compelling problem: the systematic inability of the current financial reporting system to meet the needs of users to understand the ways in which complex organizations perform and to hold their managers accountable.

This example also undermines one of the arguments in support of the current financial reporting system and against changes to that system: the need to maintain comparability and consistency across firms in the ways in which they account. In the case of Cisco, even long established and relatively uncontroversial rules on inventory valuation could not guarantee that different firms will apply those rules in the same way given the underlying ambiguity about what is being measured. This is really an argument for more information disclosure to enable stakeholders to better discern the purpose and meaning of each transaction. 


\section{A CONCEPTUAL BASIS FOR REENGINEERING FINANCIAL STATEMENTS}

\section{The Changing Drivers of Financial Reporting}

The Concept Statements that underlie the current US financial reporting systems state that "Financial reporting should provide information that is useful to present and potential investors and creditors and other users in making rational investment, credit, and similar decisions. The information should be comprehensible to those who have a reasonable understanding of business and economic activities and are willing to study the information with reasonable diligence." [Paragraph 34, Statement of Financial Accounting Concepts No. 1]. That information is communicated principally through the mandated financial statements: "Financial statements are a central feature of financial reporting. They are a principal means of communicating accounting information to those outside an enterprise." [Paragraph 6 Statement of Financial Accounting Concepts No. 1].

Of particular significance is how the quality and nature of the information conveyed by those statements is determined: "Whether at the level of the Board or the individual preparer, the primary criterion of choice between two alternative accounting methods involves asking which method produces the better-that is, the more useful-information. If that question can be answered with reasonable assurance, it is then necessary to ask whether the value of the better information sufficiently exceeds that of the inferior information to justify its extra cost, if any. If a satisfactory answer can again be given, the choice between the alternative methods is clear.

The qualities that distinguish 'better' (more useful) information from 'inferior' (less useful) information are primarily the qualities of relevance and reliability, with some other characteristics that those qualities imply. Subject to considerations of cost, the objective of accounting policy decisions is to produce accounting information that is relevant to the purposes to be served and is reliable." [Paragraphs 14 and 15, Statement of Financial Accounting Concepts No. 2].

We have quoted these at length in order to give some context to the issues that face any proposed changes to the financial reporting system. The current joint project of the IASB and the FASB to converge their conceptual statements attempts 
to deal with some of the shortcomings in these original conceptual statements that have emerged over time. That process is has just begun and it is pointless for us to attempt to replicate or replace it. But it is useful to see at this highest level what drives financial reporting, of which we focus on three issues:

1. The users of financial information and their capabilities. As the quote above indicates, such users are no longer considered to be the unsophisticated "widows and orphans" that apocryphally motivated the passage of the original securities acts in the 1930's, at the height of the Great Depression. But having a "reasonable understanding of business and economic activities and are willing to study the information with reasonable diligence" seems to be a rather minimalistic description of the investment bankers, hedge funds, credit rating agencies and institutional investors that dominate financial markets today. A $21^{\text {st }}$ century reporting model would surely give greater prominence to these sophisticated players-and the technology that they utilize to arbitrage even the slightest price discrepancy-that make the market today, as opposed to passive investors who enter the market largely through such intermediaries as mutual and pension funds.

Indeed, while fifty years ago private investors owned over $90 \%$ of all shares outstanding of US firms, their stake has plummeted to only around $30 \%$ with the share of ownership by such large financial institutions as pension funds and mutual funds having increased in the same time period from under $10 \%$ to almost $70 \%$. Moreover, while in decades past such large equity holders had an asset turnover in their portfolios of less than $20 \%$ per year, in the last few years that rate has shot up astonishingly to over 90\%, which suggests a far more dynamic trading strategy, accompanied by very different informational needs. The issue of how users use information and what form they get it in is intimately connected with the costs of financial reporting.

2. The Costs of Financial Information Processing and Reporting. The costs of preparing financial information clearly affected the original focus on the annual financial statements as the "central feature of financial reporting". They serve as summary measures of the state of the firm and its performance. Such summarization and condensation inevitably results in a 
loss of information which cannot be in the best interest of users unless the measure perfectly captures future firm value, or the costs of more detailed information exceed its benefits to users. What is the cost of preparing financial statements? The answer to that question is often complicated by the conflation of the potential cost of reporting in general, and the specific cost of meeting the current financial reporting standards. In other words, the cost induced by such complex standards as those on pensions or derivatives should not be taken as indicative of the cost of meeting any standard, current or proposed.

The fact is that the cost of maintaining and reporting accounting records has fallen dramatically with the development of software and electronic stock keeping. Thus an ERP system such as SAP can generate innumerable reports on a continuous basis without the need for the manual closing and reconciliation of ledgers that used to characterize accounting for much of its history. Data entry is increasingly automated thanks to bar coding and soon, with RFID chips, and the key change accounting software makes is to change data processing and report preparation from a variable to a fixed cost. That fixed cost keeps decreasing thanks to Moore's Law, the rise of manufacturing in China and the various other factors that have made IT so much more cost effective in the last few years, and which accountants can take advantage of.

It is also important to put the costs of disclosure against two other costs: the first is the opportunity cost when faulty disclosures harm the company, for example, by increasing its cost of capital. The other is the cost to the user of deciphering the firm's financial statements. It has been argued that the rationale for the highly aggregated system of annual statements is to lower the cost to the user of understanding the complexities of accounting. But today many users complain that the statements conceal more than they reveal and that a great deal of costly analysis is needed to reverse the accounting and find out what the statements are really saying about firm performance. Learning how to do this process of "peeling the onion" of financial statements, is, after all, the purpose of all the classes that are taught on financial statement analysis. As Hirst and Hopkins (1998) state: “Financial accounting standards allow 
companies considerable flexibility in determining which accounts are aggregated into the individual line items in the primary financial statements. Because of the difficulty inherent in assessing the relevance and persistence of these amounts, users of financial accounting information often must sort through voluminous notes and non-financial information to effectively forecast the future earnings, cash flows, or intrinsic value of a company. This wide dispersion of value-relevant information increases the direct and indirect cost of valuation activities."

The CFA puts argument about the cost of financial reporting from the perspective of their members, the existing shareholders, this way: "the most compelling argument for requiring that the reporting changes be made is that if investors must transform financial statements, and the information they contain, into a different form so that they can use the information in their decision making, then the statements and information should be presented in that form in the first place."

The issue of the costs of disclosure, however, is much more likely to be raised in terms of the physical cost of issuing financial statements than of the user in deciphering them, or even of the opportunity cost to the firm itself of incomplete disclosures. That is certainly the only way in which the term "cost" is used in the FASB Concept Statements cited above which states that disclosing better information can only be justified "subject to considerations of cost". As the CFA and others argue, a $21^{\text {st }}$ century reporting system needs to depart from a perspective that seems to serve solely the interests of managers who wish to hide behind obscure financial statements by claiming that any expansion in transparency is too costly. The bottom line is that either in terms of the physical costs of disclosure, the total costs that encompasses the cost to users of deciphering financial statements and the opportunity costs to the firm of faulty disclosures, all forces today indicate that there should more rather than less disclosure, which raises the final issue we focus on in this section, of the process by which financial statements are prepared.

3. The process of financial reporting. Financial reports are the outcome of an accounting process in which data held by the firm is transformed into publicly released information. At present that process involved a great deal 
of summarization, aggregation and condensation of information, the extent of which can be gauged from looking, for example, at the income statement of a gigantic conglomerate like General Electric, which reduces the activities of a company with $\$ 150$ billion in revenues and a "portfolio" of half a dozen operating businesses, each with individual units and divisions all over the world, to a financial statement no more than one page long.

What is the rationale for a process that clearly leads to a great deal of information loss? It is clearly an outcome of the assumptions made earlier about the capabilities and needs of the users of financial information and the direct costs to the firm of preparing financial statements. Statements meant for "widows and orphans" look very different from that desired by a hedge fund manager contemplating a buyout of a firm. The scope of reporting when statements were prepared manually should differ from one generated by the push of a button on the firm's ERP system. The question is whether the changes in these two fundamental drivers of financial reporting have been adequately reflected in the evolution of financial reporting. Clearly users such as the CFA, and even preparers such as the AICPA which instigated the EBRC or the CICA, feel that they have not. An additional factor in the development of the current systems of reports is that for much of the early history of accounting, its purpose was not providing information to investors but the stewardship of the firm's physical assets. This shift from the stewardship function toward valuation and comparative evaluation necessitates a broader, future oriented set of information.

As financial statements have proven to be insufficient for the needs of more sophisticated users, they have been expanded periodically in response to demand or the latest scandal, in a largely haphazard fashion. In some cases, the statements themselves have been reconfigured (for example, to allow mark to market accounting to reduce the dependence on historical cost) or else additional information has been provided outside the statements, through the use of footnotes and the MD\&A statement qualitative strategic information. But the centrality of the statement based reporting, as codified in the FASB's Concept Statement No. 1 has been 
retained, along with their underlying implicit assumption that it is important to restrict the scope of information provided to users in order to avoid overwhelming them (akin to the recent proposals for a condensed and simplified version of mutual fund prospectuses). The end result is a highly aggregate, episodic flow of information from the firm in which a small set of standardized information attempts to satisfy the widely varying needs of users.

This approach also implies that auditing is also centered on the mandated financial statements. Thus auditing is also episodic and focused largely on whether the firm has correctly condensed and aggregated its information into those statements (which is what "prepared in accordance with GAAP" literally means). Validating information on a more concurrent basis is held to be outside the scope of the external auditor and assigned to the internal auditors instead. But it has also become steadily apparent that the mandated statements cannot be considered independently of the underlying firm data and the firm's accounting and control infrastructure that gives rise to that data and records, manipulates and aggregates it. Thus, as with financial reporting, auditing has been periodically expanded, albeit also in a largely haphazard fashion, first to encompass general examination of controls, and with the passage of Section 404 of the Sarbanes-Oxley Act, to a detailed attestation of financial reporting controls. The lack of other audited information has also resulted in auditors becoming insurers of last resort, as users who are forced to view the firm through those statements come to see the auditors as gatekeepers for the firm, and so hold them responsible not only for the accuracy of their accounting representations, but for the decision relevance of their content.

With the financial reporting environment almost exclusively focused on the income statement and the balance sheet it is not surprising that at least some actors in financial markets have also have tended to view a firm largely through the prism of those documents. In an extreme, this can lead to forms of functional fixation, where form can trump content, as when information in the statements themselves dominate the market's reaction even when information in footnotes modifies or contradicts it. In turn, firms expend vast resources in fighting accounting changes that impact the 
income statement even if that same information is presented elsewhere and could be readily used to recalculate the reported numbers, as in the ongoing debate over stock option expensing.

On the other hand, financial markets today are increasingly dominated by professionals who are not only capable of handling highly disaggregate financial data and forming their own conclusions about it, but actively do so. Thus some analysts use the financial statements issued by firms as a resource from which they extract specific information which they insert, along with other external information, to construct their own independent model of firm performance, and discard the version presented in the $10 \mathrm{~K}$. The point that their representatives, the CFA, makes is that this is a roundabout procedure prone to distortion and error that can be avoided by giving their members the information they want in the form they need in the first place.

In summary, our working hypotheses are that a) the focus of the financial reporting system on the mandated statements constrains the analysis that users are able to perform, and, flowing from that, b) the lack of other instruments of communication lead firm managers to use those statements to signal information, requiring a continuing focus on the form of those statements, independent of their content; and c) the fact that assurance is provided on only those statements means that they have to receive disproportionate weight, regardless of their information value.

\section{Towards a $21^{\text {st }}$ Century Reporting Model}

Our conclusion from this analysis is that if the financial reporting system was being built from scratch today, it would look very different, taking into account fundamental changes in the two drivers of financial reporting. First, the dominance of market making by professional investors which includes such intermediaries as pension and mutual funds which is how most ordinary individuals now enter the market (including presumably, any remaining widows and orphans). Indeed, even those remaining individual investors, such as day traders, are probably far better educated about markets and have access to far more analytic resources and information from online and media sources than even the plutocrat investors of the 1930 s, dependent on their ticker tape machines. Second, a $21^{\text {st }}$ century reporting 
system would also take into account the reduction in the variable costs of disclosures to technology-enabled firms while at the same time taking a broader view of the cost of reporting to take into account also the opportunity cost to the firm from faulty disclosures and the cost to professional investors of having to extract the data they need from statements that were not designed for their needs. The fact is, as SEC Commissioner Glassman acknowledged, "reporting standards and mechanisms are in a 'catch-up' mode" and have failed to keep pace with users increasing sophistication or the power of their technologies which operate in very different ways from the manual systems that existed when the current reporting systems had their genesis.

Taken together, the consequence of these two changes is that a system being designed today has to rethink the entire process by which financial data held by the firm is translated into decision relevant information by users. The first thing we have to do is to recognize that this financial reporting process takes place both within the firm and outside of it, with a handover of financial statements taking place at the boundary between the firm and its users. By contrast, that part of the process external to the firm certainly does not receive the same weight as the concerns of the firm preparing the statements in the FASB's Conceptual Statements, as the CFA notes with some chagrin. However, as the forces affecting the costs and benefits of financial information have changed, it is time to ask whether the location of that handover boundary point is still appropriate: whether the firm should continue to aggregate and condense information extensively before releasing it, or whether sophisticated users would prefer to have access to more information in closer to its raw format so that they can manipulate and aggregate it as they see fit, meaning that they don't have to take as given the choices of either the firm or the standard setters.

That is not to say that firms will not prepare income statements and balance sheets, or that they will not retain their centrality in reporting. But the question is whether users should be restricted to that one perhaps self serving method of aggregation and condensation or whether they should be allowed to better see how that report was created in the first place - thus allowing them to make an informed judgment as to whether the statements can be accepted at face value or whether it is more appropriate to use the data underlying that report as inputs into their own models of firm performance. Reducing the emphasis on the income statement and 
balance sheet will not only increase the scope of information available to the market, but would also reduce the likelihood of functional fixation, since it would become clearer that the format chosen by the firm in accordance with GAAP is just one way of presenting that information, and not the only way.

Admittedly, any recalibration of the financial reporting process would require many critical issues to be addressed, including a) the tradeoff between meeting the needs of sophisticated users for more data against the concerns of the firm's managers about revealing competitive data, b) what is gained and what is lost when firms process information less and users have to do more, and c) how much assurance will be provided with the information and who will provide it.

These three are not independent issues, since aggregation is an extreme form of information processing in which a great deal of information is potentially lost. It also allows for those who have access to the raw information, the firm's managers, to shape the degree and form of summarizing that suits their interests best. At present, managers constrained only by their ability to get their interpretation of GAAP through the auditor, direct their energies towards making one metric of firm performance, earnings per share, as favorable for them as possible. Reducing the degree of pre-processing and aggregation of information by the firm would presumably also reduce the ability of firm managers to manipulate that information. On the other hand, it would put more of the burden on users to understand perhaps complex, firm specific accounting issues, and while some, such as those the CFA represents will clearly welcome this, those closer in capability to the "widows and orphans" may not-assuming that they actually depend on the information directly in the first place, as opposed to leaving such matters to professionals in mutual and pension funds.

A reengineered financial reporting system will inevitably impact the role of auditing. If more information is issued more frequently, auditing will have an impetus to move away from an annual focus towards a more continuous auditing model. Moreover, with more disaggregate information being reported, auditing will also shift its emphasis away from verifying the way in which the firm aggregates and condenses its data, towards a broader conceptualization of assurance, particularly data-level assurance.

This conceptualization of the forces driving the reengineering of the financial reporting process is not unique to us. While not all will agree with all the 
particulars describe above or draw the same conclusions, it is in broad terms the underlying motivation behind the initiatives of the CFA, the CICA and the AICPA amongst others, and shades of these views can even be detected in the harmonization project of the conceptual models of the IASB and the FASB. However, starting at the same starting point does not guarantee ending up at the same place. Political and constituent pressure will lead the bodies behind the various initiatives to produce outcomes that vary in the degree of change that is proposed.

Building on the mandate imposed by the EBRC on the Galileo project to "presents ideas that are further departures from current practice", we build on this foundation a test bed for innovative, technologically enabled solutions to the problems of financial reporting. The aim is to complement the more pragmatic approaches to change with a test bed for the development of advanced tools that will slowly be integrated into the change process.

\section{BUILDING BLOCKS OF A FINANCIAL REPORTING TEST BED}

Our test bed for a new financial reporting system is built on the foundation outlined above, of sophisticated users, technology driven decreases in the direct costs of report preparation and increases in the demands for data of the technologyenabled analytic models of users and a rethinking of how much manipulation of data is undertaken by the firm as opposed to users. Moreover, technology is not just the underlying cause of these changes in the drivers of financial reporting, but is also extensively relied upon as the medium and the enabler of the test bed. As with the X-29, without technology this model will crash and burn. And to continue that analogy, decisions have to be made at this stage as to the basic parameters of the test bed-the equivalent to the shape of the wings in the X-29. Doing so inevitably results in taking a general goal that may have widespread acceptance and reducing it to a more constrained model whose particulars may generate considerable disagreement. But disagreement is a perquisite for debate and we welcome it as the driver of progress rather than something to be avoided. Recall that by definition this project differs from others, such as the EBRC, in that it does not eschew the possibility of radical innovation because of the need to maintain a consensus.

With that caveat we lay out our personal conclusions about how the changes described above would affect a 21st century reporting system. These conclusions 
serve as the fundamental building blocks for our test bed, upon which a more detailed structure can be constructed and "flight tested".

\section{BB1: One Set of Books}

It is an old saw in business that firms maintain multiple sets of books, one that tells the real story of the firm which is only made available to managers, and another set of accounts that is reported to external parties. To some extent that dichotomy may have made sense in a world of highly aggregated and simplified reporting to unsophisticated users in which using financial statements for internal management purposes could lead to flawed decision making. But it hardly can be justified when one of the main uses of financial reports by users is in assessing how well management is running the firm and what future prospects they see for the firm and its assets. Firms in today's information age economy, where value is driven by knowledge and technology, have to be run using sophisticated management control and measurement systems. That is what managers look at, and the output of that control system is what users-especially the hedge funds that increasingly drive markets today-would like to access and evaluate for themselves, to the degree that confidentiality of proprietary information makes possible.

The main point, however, that we draw from the prior analysis of the technological drivers of financial reporting change is not that reporting based on one set of books is desirable, but that it is already here. Firms today in a very real sense consist of a series of processes built on a large, common dataset, to be specific, a data warehouse, which is defined as "the 'single point of truth', the 'corporate memory', the sole historical register of virtually all transactions and important operational events that occur in the life of an organization". With the creation of such a system providing instant access to such a comprehensive set of data, financial reporting becomes to a large extent just a subset of the possible uses of the data warehouse. While a critical element of financial reporting consists of subjective judgments, such as of contingent liabilities, nonetheless much of financial accounting is comprised of aggregates of transactions and once a data warehouse exists, reporting those is for all practical purposes, no more costly than pushing a button. Thus in our test bed internal and external reporting will be based on the same underlying data, based on the same underlying MC system, differing 
only on-to use appropriately, a term borrowed from XML concepts-the stylesheet which determines presentation format.

Importantly, a data warehouse and the analytic and reporting software it supports is not created just to prepare an annual income statement and balance sheet, but because it supports the management control systems that help run the company. This is a revolutionary development as far as the cost of financial reporting is concerned, a matter of such great concern to the writers of the FASB Conceptual Statement, because it essentially means that financial reporting (at least of its non-subjective components) is a bonus that comes for free with the construction of the firm's management control systems. For example, SAP comes with built in modules for financial reporting, activity based costing and even auditing, Moreover, being an endogenous part of the management control system means that the financial reporting system can built upon and takes advantage of the very sophisticated sensing and measuring capabilities of that ERP based control infrastructure of the firm that helps populate the data warehouse with fresh data on a real time basis.

The key point of the one set of books building block is that when financial reporting arises organically from the management control system, it shifts the burden of proof from demanding information to supplying it. There may well be good reason in terms of proprietary information to obscure the details of sensitive firm data, but it much harder to make the old argument that is too costly to report something, such as segment data, when that data already exists in, or can be easily constructed from, the data warehouse. In other words, once the cost obtaining transactional financial reporting information is eliminated, the basic presumption will change from "does releasing more information satisfy the cost versus benefits criteria" to "what justifies not releasing this information, since it is freely available?"

It is this shift to one set of books with financial reporting a subset of the firm's management control data system that makes it feasible to open up for debate the fundamental question, discussed above, of where the boundary should be drawn between internal and external reporting and the degree of pre-processing the firm should undertake before release, versus letting users have access to more of the underlying content of the data warehouse. 


\section{Technical architecture to implement BB2 in test bed:}

- Based on the holistic view of the corporation, drawing on integrated corporate ERP systems, any remaining legacy systems and Web facing systems. On top of these a monitoring and control layer aimed at comparing corporate measures and corporate performance models (Figure 3).

- An OLAP (Online Analytical Processing) cube display allows for the aggregation and analysis of the data in the warehouse to meet various management needs, including internal control, financial reporting and comparison, auditing and customer relationship management. The OLAP layer allows for the extraction from corporate systems of an aggregate multidimensional view whereby, for example, sales figures can be drilled down into sales by department, sales by product, sales by program or sales by job function.

- Transactions enter the warehouse tagged in a XML derivative language, such as XBRL and XBRL-GL, to facilitate subsequent analysis as the OLAP level and reporting both internally and externally.

- Given the differing needs of a wide variety of stakeholders, both internal and external to the firm, stylesheets as in XML will allow for multiple types of pre-prepared reports (figure 4).

- Not on paper - a flat static model on paper cannot adequately represent the characteristics of an ongoing business. The model must be dynamic in presentation, able to show variable hierarchies, and able to be re-organized across the user needs.

- The different users of can benefit from a wide set of information support, rich in visuals such as graphs and other forms of corporate representation including Web enriched video and audio explanation of key issues.

- External reports are to be XBRL - XML - enabled for intra-company and inter-company interoperability as well as easy flow down the data value chain.

○ XBRL/GL enabled general ledger accounts

- Enriched footnote with tagged content 
- Taxonomies of key types of footnotes

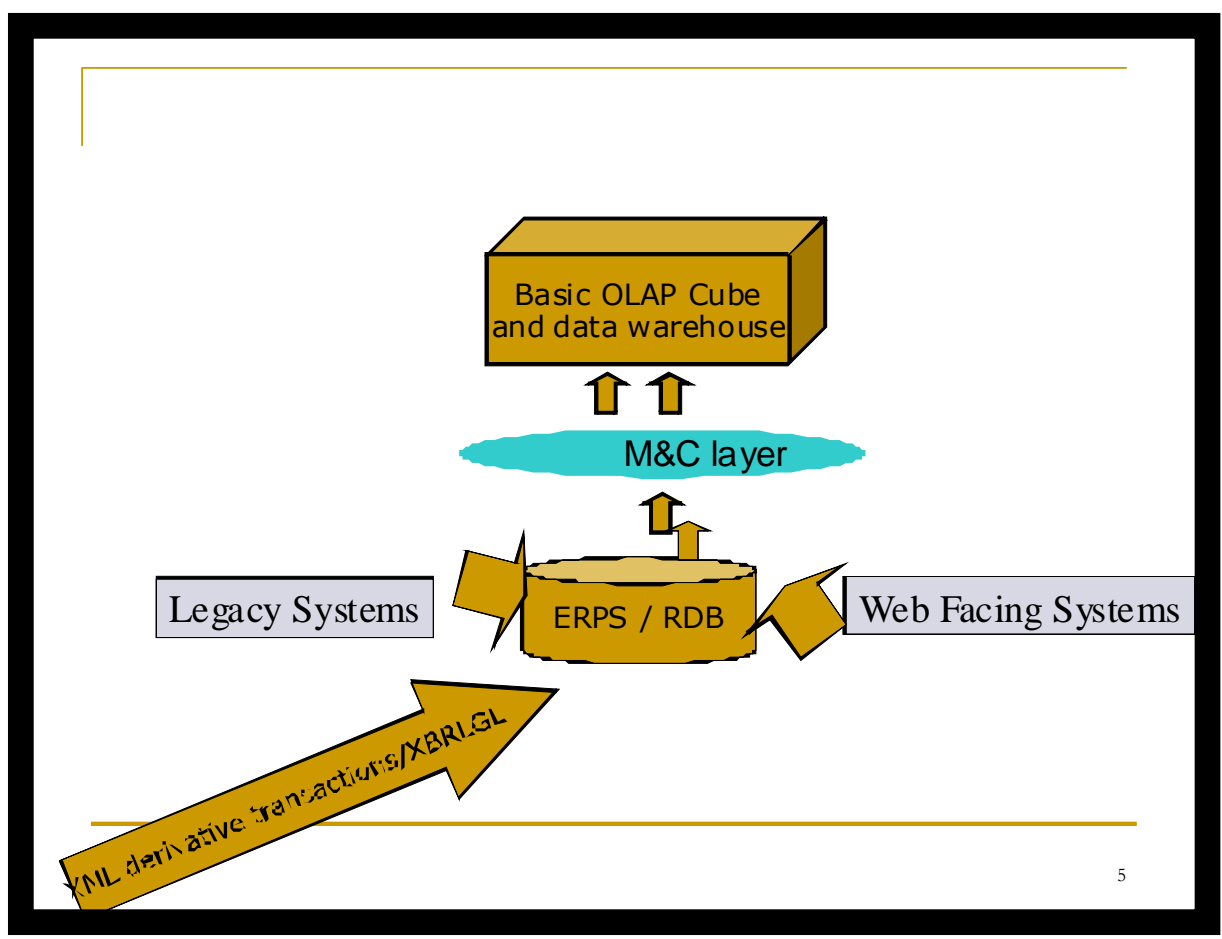

Figure 3: The monitoring and control layer

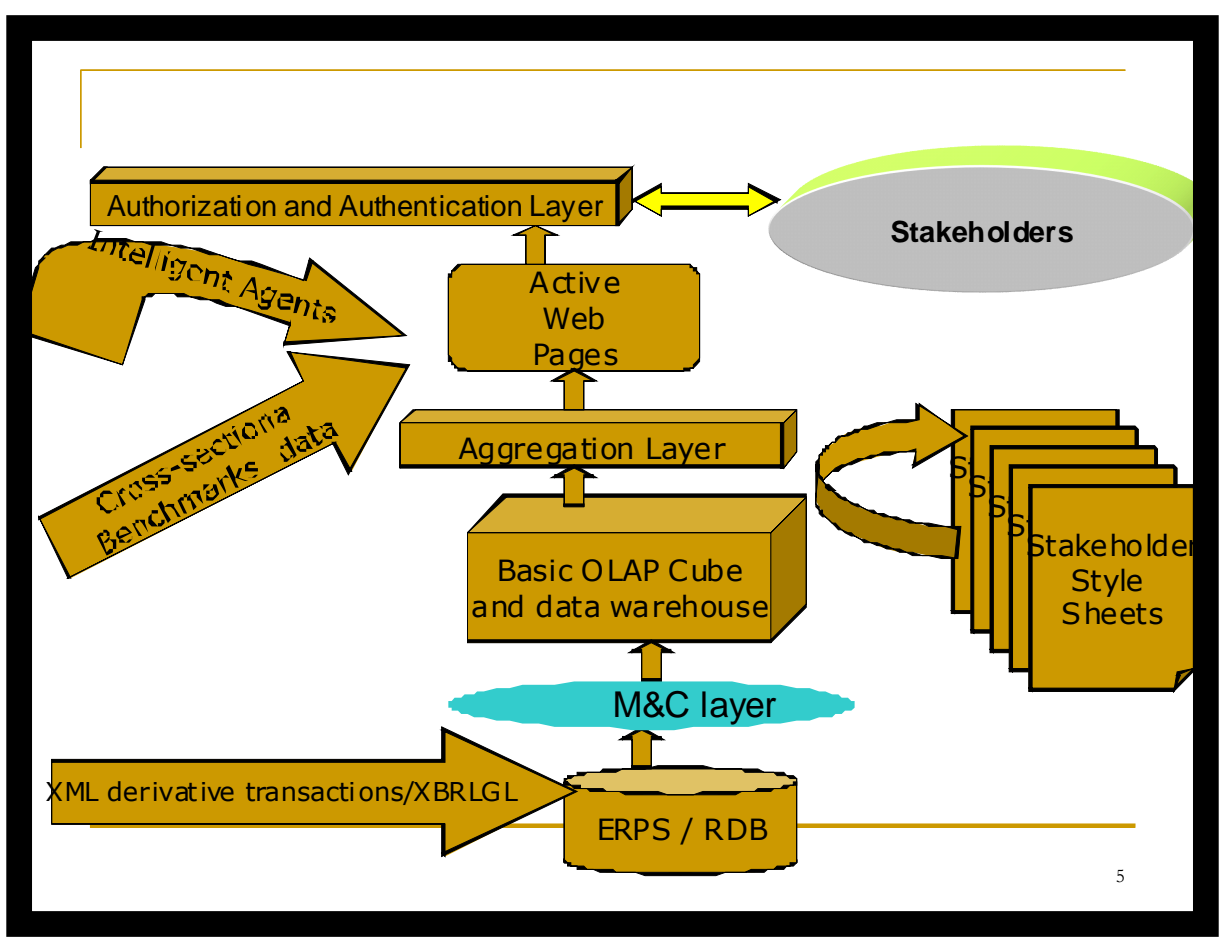

Figure 4: Basic Stakeholder Driven Disclosure Technology 


\section{BB2: When in Doubt, Disclose the Facts}

BB2 is the founding principle of the new reporting paradigm: that users should have the opportunity to process data as they see fit, rather than having to accept a one size fits all method chosen by the firm or by accounting standards. In short, to err on the side of less pre-processing, not more. It is the immediate conclusion from the hypothesis outline above, that user of financial reports today are not unsophisticated "widows and orphans" with limited ability to process financial information. Rather, users are financial intermediaries, such as analysts, fund managers and institutional investors whose main problem is a lack of information, not information overload.

A new reporting system must start with this reality and ensure that while the needs of those consumers who only want the summary now provided by the mandated financial statements continue to be met, the needs of the more sophisticated users are also catered to by providing more disaggregate information not processed by the firm or screened through a GAAP filter. The advantage of BB1 is that it provides the test bed with the capability of stylesheet driven system of different reports for different users. Getting away from "one size fits all" means that users who only want the one page income statement summary of firm performance do not constrain those who want to make their own assessment based on the underlying data - or vice versa. Another advantage of this increased reliance on rawer data is that it avoids delays in the release of information until a consensus can be reached on the "best" way to process the information, which almost inevitably results in a common denominator approach that reduces the usefulness of the disclosures.

For example, one of the main controversies facing accounting today is option based compensation: whether they should be counted as an expense in the first place; if so, whether as a line item on the income statement or only in a footnote; and how the options are to be valued in the first place. Disagreement over the latter is often cited by firms are reason to delay indefinitely any final decision on the first point. Especially in a setting such as this, where legitimate arguments on all sides preclude consensus, $\mathrm{BB} 2$ provides the solution of letting the market decide by using the technical architecture of BB1 to allow the users to see the data in many different ways and make up their own minds with all the possibilities in front of them and not just one. For example, income with and without expensing, footnoted 
and as a line item and under various valuations schemes, such as Black-Scholes and binomial. Indeed, if sufficient granularity is provided to the data, users would be able to recalculate some aspects as they saw fit. This illustrates the mixing of analytic and computer technology to improve the reporting model in ways that were not even conceivable a decade ago.

To give another example, consider the continuing challenge of asset valuation. While much of the traditional balance sheet currently uses some form of modified historical method, with inflation or just the passing of time, the accuracy and relevance of historic cost valuations tends to decrease. Furthermore with the evolution towards an information society, the most valuable intangible assets tend not to be valued on the reports at all. In order to present a more relevant economic measurement, more complex and stochastic approaches will have to be adopted. The literature makes distinctions such as exit value valuation, current cost, market value, replacement cost new, and now fair value. The drawback is that many of the proposed alternative valuation methods are inexact and potentially very costly to utilize and all highly subjective, meaning that any gain on the relevance objective is at the expense of reliability.

Consequently, where valuation is difficult BB2 suggests disclosure at a level of granularity which will allow users to make their own assessment of value or apply the valuation model they prefer. Most users will typically state that they rather get the basic data not a datum that is pre-computed and manipulated or obscured by management. In other instances where valuation is very specific to a particular type of situation we suggest valuation and disclosure.

Now it is to be admitted that while BB1 essentially discusses what already exists, or will soon do so given independent advances in technology, BB2 personifies "ideas that are further departures from current practice." The main argument against BB2's premise of essentially shifting the point at which the firm hands over information to external users in the direction of less pre-processing is that users lack the ability or the willingness to deal with more information, suffering from lack of knowledge of key accounting issues and from information overload. As one commentator on an earlier version of this paper put it: "Financial statement users are not always as sophisticated as one might think, even experienced analysts. They simply do not understand, or are unaware of some of the more complex issues accountants currently address (say, for example, pensions 
and financial instruments). Analysts generally recognize this and willingly leave such matters to accountants to deal with on their behalf. The shortcomings of the current system that the analysts tend to complain about are often quite mundane and sometimes involve issues that are intractable (but the analysts don't realize it). Some of the analysts I have heard from clearly want standards to help them make sense of the information companies provide. The supposition that analysts would be able to go data mining in publicly available corporate databanks to develop the information they need is laughable. The analysts I know would have neither the time nor the ability to do that. In my experience, analysts are barely able to cope with the volume and nature of information currently available to them, given the outputs they are expected to provide. For example, some analysts have to sift periodically through the entire universe of public companies, or substantial subsets of that universe, to identify potential candidates for closer scrutiny. They do so on the basis of a very few, quite crude analytical screens based on current reporting. They could do no more with the models available to them. Building better models to use raw corporate data is likely impracticable. If it were attempted, it would likely largely replicate the companies' accounting systems. Companies might find it attractive to shift the cost and effort of external financial reporting onto the shoulders of the users, but would not be able to avoid the cost and effort of maintaining their own systems for internal reporting."

We quoted this criticism at length because it makes the case against BB2 so comprehensively, and indeed, goes further, in attacking the fundamental principles discussed earlier about users' capabilities and cost of information processing and reporting that we take as the drivers of change in financial reporting. As we discussed then, findings of functional fixation and scandals involving analysts, provide some support for this skepticism. But ultimately we dismiss it as presenting a view of users as naïve and lackadaisical that simply does not fit the sophisticated users at the margin that make markets today, even if they do exist amongst the bulk of users.

The best counterargument for this criticism comes not from us, but from the representatives of those sophisticated users, the CFA, which bluntly addresses the very issue underlying BB2: "A frequently heard argument against standard setters' proposals to require additional disclosures is that investors already suffer from information overload and cannot assimilate any more. We counter that more- 
accurate and useful information never results in overload. First, whether it is used by investors in every case does not bear on the fact that such information should represent true and fair value. Second, what burdens investors is extraneous information-disclosure that neither informs nor enlightens the typical boilerplate prose that remains in companies' financial reports year after year unchanged or amended in any way. It would appear to many investors that much of the currently available information is designed solely to meet minimum legal requirements for disclosure while providing little of substance to reach the sunlight. Useful disclosure communicates information clearly and succinctly, in formats designed to convey the substance of the company's current sources of value and how those sources of value have changed and why. Legal obfuscation and boilerplate do not."

\section{Technical architecture to implement BB2 in test bed:}

- The capabilities used to implement BB1 facilitate the provision of information in any format to any user in a variety of easily customizable reports.

- User overload can be avoided by the development of dynamic stylesheets that allow for easy switching and comparison amongst alternative perspectives on the data, as in the options example. Demonstrating this capability was a missed opportunity in the EBRC sample reports, each of which presented different ways of reporting but using different rather than the same data.

\section{BB3: Support estimates and competing aggregation methods}

This building block is a natural corollary to the one above. Estimates, most notably, accruals, are what distinguishes net income from cash flows, as FASB Concept Statement No. 1 makes clear. Making estimates for too long has been considered to be an art form and not a science, and therefore not subject to systemization. Certainly some estimates are more rigorously supported by data (inventory again, for example) than others (contingent environmental liabilities, for instance). But all presumably are arrived at through some process, if no other reason than the need to pass the scrutiny of the annual audit.

A 21st century reporting system with its enhanced capability for communication and access to the underlying data warehouse should have the 
capability to ensure that estimates are accompanied by details as to the process by which they were arrived. For example, estimates could hyperlink to both the basis of the estimate as well as the method of the estimate, including a comparative table of how the particular estimate was performed in the past. If possible, the calculation of alternative calculations should be facilitated to the user, especially in instances where the default estimation method is inherently arbitrary, and there is little justification for the claim that the method the firm chooses is the best or the only way, such as with depreciation of assets.

Comparability is a driving force behind the existence of accounting standards, and if it is known that users, dissatisfied with current disclosures, are doing their own calculations of estimates, then in the interest of a greater vision of comparability, it is better to offer alternatives to all users. Indeed, some data intermediates and credit entities have over the years evolved their own types of bottom line calculations that are different than the ones provided by companies. For example, S\&P uses an additional calculation to take out the effect of stock options granted prior to the calculation of earnings per share.

BB 4 has also been criticized in its earlier incarnations, with the prior cited commentator stating: "The paper seems to assume that estimates are based in all cases on data entered into a business system. For relatively routine estimates, such as bad debts in receivables or inventory obsolescence, that may often be so. For some other estimates, often key ones, there is no data system supporting management's estimate." If that is indeed the case, then surely the primary requirements of financial reporting, as stated in the FASB Conceptual statements, of relevance and reliability should by themselves drive disclosures of how such estimates are obtained, if they are indeed not supported by the firm's data systems. The electronic format of disclosures in this reporting model enables data points such as estimates to be enriched through links to supporting material. Being hyperlinked, they would not overwhelm users, who would only click through if they felt a need and had the sophistication to understand that material.

\section{Technical architecture to implement BB3 in test bed:}

- Hyperlinks, "what if" scenarios through macros embedded in spreadsheets. Links to authoritative standards and guidance as to the nature and content of estimates and accruals, such as their timing, valuation criteria and degree of reliability. 


\section{BB4: Provide Data with Context}

Consider this "map" that conveys the fact that someone is at Mt. Lander:

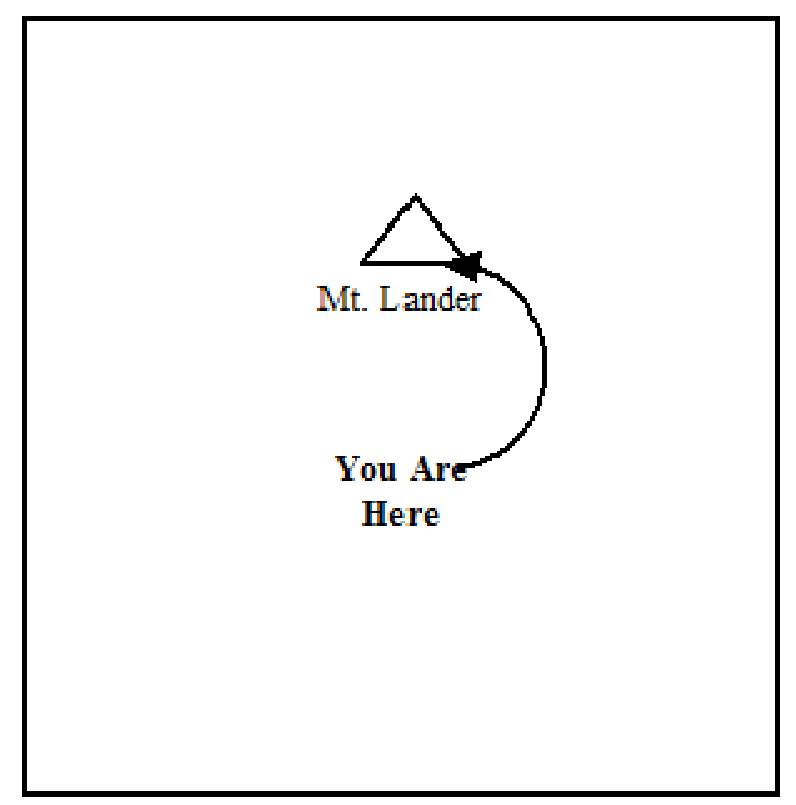

Figure 1: Data and context

Contrast that with a topographic map of the Continental Divide in the United States. It conveys the same information, but also a great deal more context that places the party's location in perspective. For example, different colors are used to indicate land, lakes or intermittent water supplies. Topographic contours link together points of common altitude, while their density indicates the rate of ascent. All that information facilitates a user of the map from efficiently and safely determining how to travel across this terrain and what they would find once there.

It is this notion of context that will be an essential basis of a new reporting system. As one financial accounting put it: "For a number to be useful, it must be compared to another number. For example, is it good or bad for a company to report a gross margin of 22 percent? Without additional data, you can't tell. To answer this question, you must know what the gross margin was in prior periods, what the budgeted gross margin is now, and what the industry average is. Only after you have compared this gross margin to the 20 percent gross margin in prior periods, 21.5 percent budgeted amount, and 19.5 percent industry average can you report that 22 percent is favorable. Too often companies fail to include comparison data in their reports." 


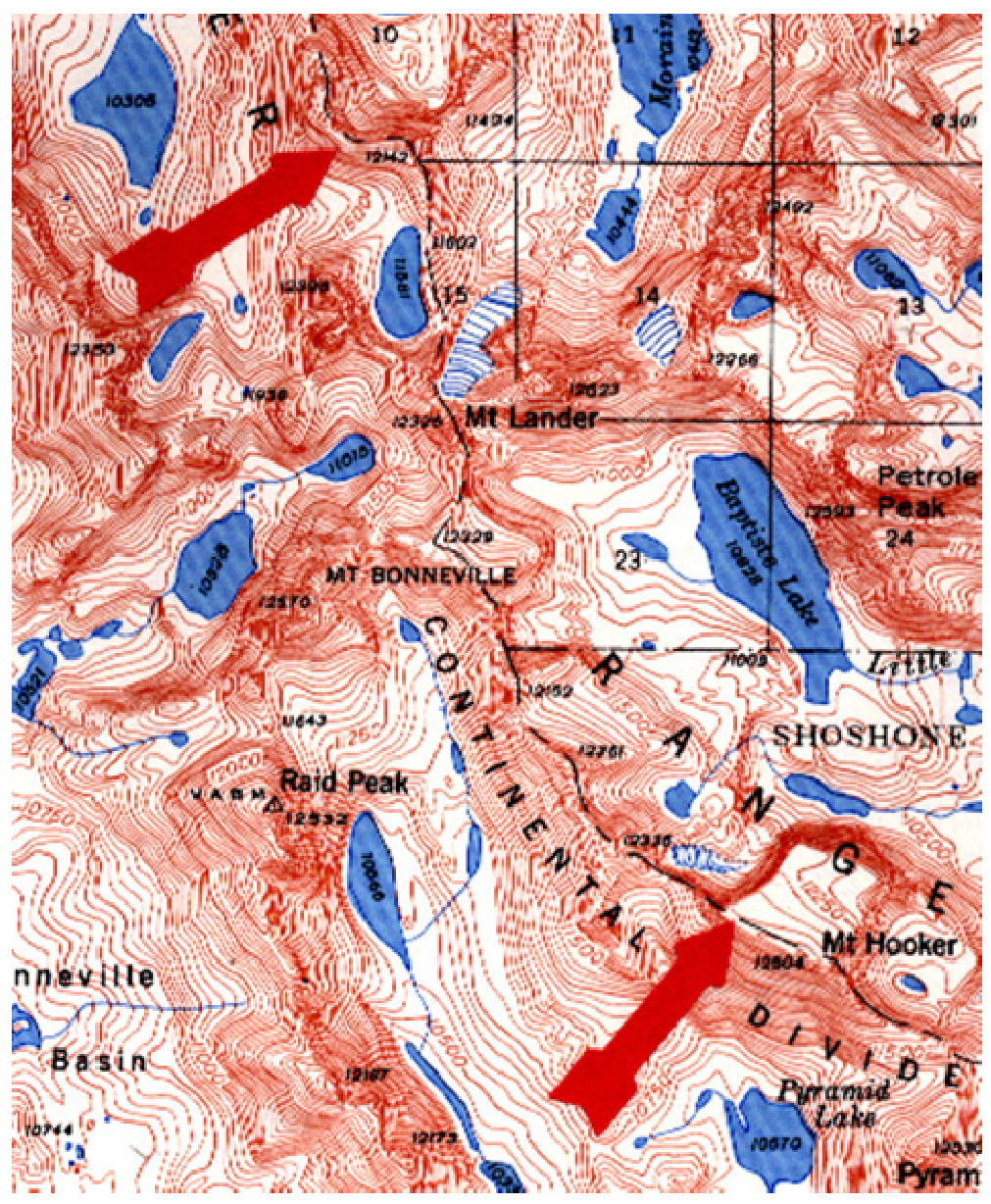

Figure 2: Increased context in a map setting

Interestingly, FASB Concepts Statement No. 2 also discusses financial accounting in terms of a cartographic map, but its main focus is on the completeness of the map and not its inherent characteristic of placing data into context: "An analogy with cartography has been used to convey some of the characteristics of financial reporting, and it may be useful here. A map represents the geographical features of the mapped area by using symbols bearing no resemblance to the actual countryside, yet they communicate a great deal of information about it. The captions and numbers in financial statements present a 'picture' of a business enterprise and many of its external and internal relationships more rigorously—more informatively, in fact—than a simple description of it... A 'general purpose' map that tried to be 'all purpose' would be unintelligible, once information about political boundaries, communications, physical features, geological structure, climate, economic activity, ethnic 
groupings, and all the other things that mapmakers can map were put on it. Even on a so-called general purpose map, therefore, the cartographer has to select the data to be presented. The cartographer, in fact, has to decide to serve some purposes and neglect others. The fact is that all maps are really special purpose maps, but some are more specialized than others. And so are financial statements. Some of the criticisms of financial statements derive from a failure to understand that even a general purpose statement can be relevant to and can, therefore, serve only a limited number of its users' needs."

The point of the technology enabled reporting system we develop in our test bed is that many of the constraints and hard choices about what data to include and what to exclude that underlie the Concept Statement's analogy no longer bind. To continue that example, the prior building blocks create an environment in which multiple types of specialized papers can be created on demand by the user, so that they are no longer constrained to use the one size fits all "general purpose" map. In an interactive system it is possible to work backward from user needs to the provision of data than to be restricted to be all things to all people because of the necessity of pre-processing information: the exact difference, in other words, between the paper route maps obtained from the AAA and the electronic maps at www.mapquest.com which the user can zoom in or out and on which he can specify that hotels or tourist attractions be mapped.

\section{Technical architecture to implement BB4 in test bed:}

At a minimum, BB4 requires the extensive use of tagging technology, such as XBRL and XBRL-GL, so that data is "self describing" and easily transportable across applications and stylesheets without losing contextual information. But no single piece of data can stand alone. To be truly useful to users, data must be placed within a broader context, its relationship to other data made obvious in much the same way as the topographic contours do on this second map.

BB1 creates a flexible alternative to the current reporting technology that will facilitate the distribution of disaggregate information, on a need to know basis, in variable format, and in short time intervals so that each one of the company's stakeholders will get their choice of presentation with appropriate context. This technology has two main components, the back end and the front end part of the technology. The back end contains the corporate database (Online Transaction Processing System) and the data warehouse (Online Analytical Processing) of the 
company. It is unlikely that most users will get access to the organization's OLTP for reasons of confidentiality and will instead interact with specialized dedicated applications that will use OLAP type of techniques to extract and aggregate data.

Users of the information will be able to retrieve information in multiple formats. Conceptually, we see two potential approaches, namely, XBRL type of reports and user driven reports. Using the framework of XBRL it is possible to facilitate numerous types of reports that can efficiently be parsed by computers. Alternatively, custom reports could be generated by users by gaining access to the specialized reporting data warehouse. The utilization of technology expands and improves the representational capabilities of business reporting. The characteristics of these reports will be driven by the overall goal of providing context for the information provided: Figure 7 shows a three dimensional display of sales by month, product and region. The "virtual cube" could be composed of many dimensions (more than the three in Figure 7) by improved visualization or by the display of multiple tables, for example with a three dimensional cube for each division for the four divisions of a company.

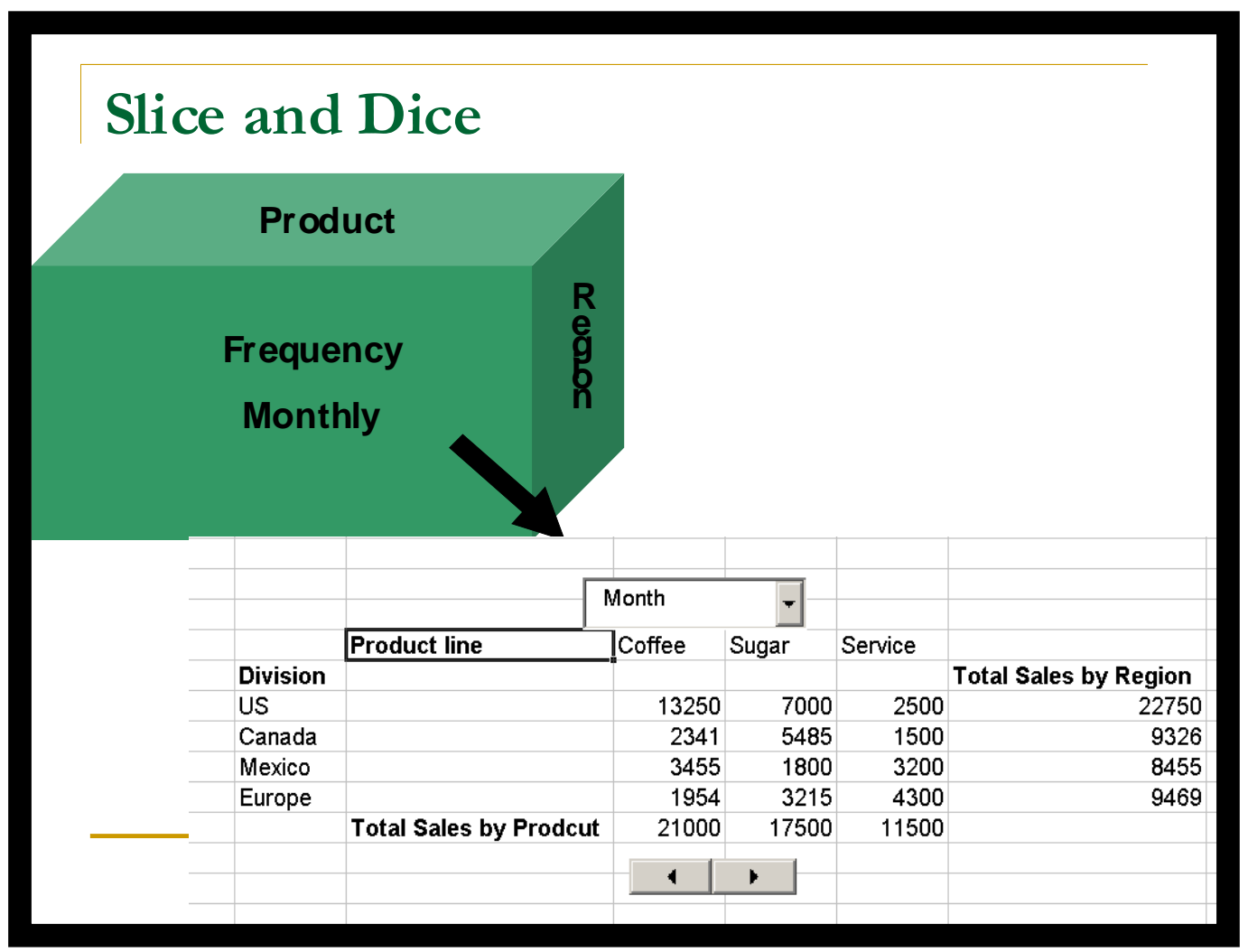

Figure 7: OLAP breakdown of data 
Another driver of context is the drill down capability of technology based measurement and reporting. While the basic concepts relative to drill-downs are trivial, their actual capabilities can substantially improve the corporate measurement and disclosure. Drill-downs allow the user to disaggregate information provided as an aggregate. For example yearly sales could be drilled down to sales by month, by division, by product and all the way down to a specific transaction, and this transaction scrutinized in relation to its contractual terms, timing, levels of approval, and controls. Of course, external users would the extent of this drill down more constrained than for an internal user, as the details of the data begin to impinge on the firm's confidentiality.

Having a drill-down capability in the test bed is the medium to bring about the recalibration of the reporting process discussed above. Traditional reporting is firm driven with all disclosure choice done by the firm's managers. While voluntary disclosures expand on the GAAP minimum, this is nonetheless very much a top down form of reporting in which the user has little choice and the discloser can potentially manipulate reports to support a desired story. The drill-down capabilities, based on the capabilities resulting from implementing BB1, BB2 and $\mathrm{BB} 3$, changes the business measurement process by having the firm provide access to a large set of basic data aggregated along key choices that the discloser makes. On the other hand, the user has the option, within the limits of the information made available, and the toolset (e.g. OLAP, stylesheets, spreadsheet downloads, aggregation functions, hyperlinks) to choose a set of views of the business entity not necessarily anticipated by the measured entity. User driven disclosure represents a very different set of premises where the disclosure are context driven, directed to the users' needs and competencies.

The scenarios in the figure below illustrate the kind of context that users would likely find useful if they could obtain access to it.

\section{Objective}

Performance evaluation

\section{Contexts}

- See high level reports of the company

- Find the same type of comparable reports

- Compute key performance indicators that give early warning 
Cash flow availability

Malfeasance issues

- Round trip transactions

- Front-ending on contracts

- Inappropriate capitalization

\section{Malfeasance issues II}

- Burying results into mergers

- Reasons for a big bang

Evaluating performance of subsidiaries and related entities and are of easy comparability

- See summary cash flow

- Identify transactions that should be excluded from cash flow such as pledging of receivables, acceleration of collections, delay in supplier payments

- Exclude these out of cash flow

- Break cash flow generation by sub-units

- Exclude / separate cash flows from financial subsidiaries

- Extract cash flows from loans and other forms of indirect financing

- Drilling down into transactions using analytical filtering- e.g. large transactions, end of quarter transactions, transactions with certain partners

- Identifying the nature of transactions through their documentation

- Tying transactions to their documentation

- Separating sub-entity results

- Clearly identifying inter subentity activity

- Drilling down to details and support of reserves

- Cut business reports by segments

- Look at segments as individual entities, apply analytics to compensate for consolidation effects

- Have access to these consolidation effects 
Understanding regional markets
- Cut business report by segments

- Cut segments by region

- Obtain results by region and by product

Figure 8: Context based user driven disclosure

Allied to drilldowns is the power of the hyperlinks. With Web technology objects can be linked through Web addresses of other objects. Hyperlink technology allows for linking objects of different nature and this addressing can be used for establishing, delimiting and determining different types of relationships. For example, XBRL instance documents can be pointed towards the taxonomies that define data relationships, Web pages can incorporate links to related pages, and transactions can be hyperlinked to remote databases bases with supporting documents, all in the interests of providing as rich a context as possible for users to utilize to the extent that they need and can absorb.

\section{BB5: "Auditability" must be an inherent characteristic of a business reporting system}

The only meaningful reports are credible ones and the basis of credibility in business is independent assurance. Hence the ability to audit financial information has to be built in to the financial reporting system, rather than having the auditor as a literally external inspector of the system's final output. Continuous auditing must be incorporated into the firm's management control infrastructure from which external reports are extracted. From the data level upwards there must be assurance that information flows throughout the firm are secure and accurate. In particular, with less preprocessing of information and more disaggregate data being reported, data level assurance will become essential. In other words, as reporting expands beyond the mandated financial statements, so must the scope and reach of auditing.

\section{Technical architecture to implement BB5 in test bed:}

There is an intensive research program into continuous auditing and its relationship with continuous reporting (Alles et al 2002, 2004, 2006). May ERP systems already have audit capability built in and independent software products such as Approva and ACL Caseware are now entering the market. But much work needs to be done on the mechanisms for integrating control monitoring and data 
assurance into the information infrastructure of the firm that supports both continuous auditing and financial reporting.

\section{BB6: The business reporting test bed is a process and not an outcome}

This is more a philosophy than a building block, but it is listed as one because it is something that needs to be always kept in mind. A test bed is a means towards and end and not an end in itself. It is not expected to be put into practice as is but to serve as a device to experiment with new technologies and techniques that can be migrated into practice through a change management process. In addition to technical development substantial education and evolution must happen for radical proposals to gain acceptance, such as BB2. It needs to be kept in mind that change that seems glacial going forward often looks dramatic in hindsight. For example, web-based reporting, a product of the nineties would not have been even conceivable even twenty years earlier but it is now part of the basic skills of the majority of information users and presents undeniable improvement over the traditional paper based model. The lesson is that any new reporting model must be dynamic, with deliberate built in obsolescence, so that it is continually updated as technology changes. It is precisely because no such mechanism is associated with the existing reporting system that there has been great difficulty in changing it in response to technological advances.

\section{CONCLUSION}

In this paper we issue a call to take a fresh approach towards the business reporting model to make it compatible with the 21 st century information age economy. As technology is the driver of that economy, so it is the fundamental basis of the new reporting system, both as a tool for measurement and communication of firm performance and conceptually, in helping shape expectations for what is possible in a reporting system. Applying the lessons from earlier technology implementations, the best outcomes arise when processes are changes to match the capabilities of the technology rather than using technology to simply existing processes. Hence we argue that the kind of piece meal change proposed to the reporting system over the last few years will not result in truly innovative improvements. Instead what is needed is a collaborative effort to create a test bed for experimenting with change to the business reporting model, without preconceptions or constraints, so that it is truly of the 21 st century. 


\section{REFERENCES}

ALLES, M.A.; KOGAN, A.; VASARHELYI, M.A.(2002): "Feasibility and Economics of Continuous Assurance", Auditing: A Journal of Theory and Practice, vol. 21(1): 125-138.

BERESFORD, D.R.; BUCKNER, C.O. (1978): "Segment Reporting Practices", The CPA Journal, December: 37.

ALLES, M.A.; KOGAN, A.; VASARHELYI, M.A.(2004): "Restoring Auditor Credibility: Tertiary Monitoring and Logging of Continuous Assurance Systems", International Journal of Accounting Information Systems, vol. 5 (2): 183-202.

ALLES, M.A.; KOGAN, A.; VASARHELYI, M.A.(2006): "Continuous Monitoring of Business Process Controls: A Pilot Implementation of a Continuous Auditing System at Siemens", International Journal of Accounting Information Systems, vol. 7: 137-161.

BOTOSAN, C. (1997): "Disclosure Level and the Cost of Capital", The Accounting Review, Vol. 72 (3): 323-349.

CFA INSTITUTE (2005): A Comprehensive Business Reporting Model: Financial Reporting for Investors.

DAUM, J. (2002): Intangible Assets and Value Creation. John Wiley \& Sons.

DAVENPORT , T.H.; SHORT, J.E.(1990): "The New Industrial Engineering: Information Technology and Business Process Redesign", Sloan Management Review, vol. 11 - 27.

FRIEDMAN, T. (2005): The World is Flat: A Brief History of the 21st Century. Farrar Straus Giroux.

GREENSTEIN, M.L.; VASARHELYI, M.A. (2002): Electronic Commerce: Security, Risk Management, and Control, McGraw Hill.

HAND, J. (1990): "A test of the extended functional fixation hypothesis", The Accounting Review, vol. 65 (4): 740-763.

HIRST, E.; HOPKINS, P.(1998): "Comprehensive Income Reporting and Analysts' Valuation Judgments", Journal of Accounting Research, vol. 36: 47-75. 
JOHNSON, H.; KAPLAN, R.(1987): Relevance Lost: The Rise and Fall of Management Accounting, Harvard Business School Press.

LEV, B.(2001): Intangibles: Management, Measurement, and Reporting, Brookings Institute.

VASARHELYI, M.A.; HALPER, F.(1991): "The Continuous Audit of Online Systems", Auditing: A Journal of Practice and Theory, vol.10 (1): 110-12

VASARHELYI, M.A.; GREENSTEIN, M.L.(2003): "Underlying Principles of the Electronization of Business: A Research Agenda", International Journal of Accounting Information Systems, vol.49: 1-25.

VASARHELYI, M.A.; ALLES, M.A.; KOGAN, A.(2004): "Principles of Analytic Monitoring for Continuous Assurance", Journal of Emerging Technologies in Accounting, vol. 1 (1): 1-21. 